knife). In order to gain space for the operative procedures I first did a sub-mucous resection of the septum. The operation was performed under morphia and scopolamine with local applications of cocaine paste.

At the operation no sign of pus or secretion was seen. The walls of the ethmoid cells and sphenoid sinuses were thin.

After-history : August 13 operation, August 19 nasal condition good. V.O.D. without lenses 6/15-4 (i.e., saw two letters out of six on 6/15 line), central scotoma for green, but the red and blue scotoma was no longer present. The appearance of disc was the same as on August 11.

August $26:$ V.O.D. $=6 / 15-3$. Upper and lower nasal edge of disc not distinct, pink in colour. Lower temporal edge distinct and white. Scotoma for colours no longer present.

September 4: Cloudiness on nasal side of disc disappeared, outline of blood-vessels quite clear, edge of disc more distinct.

September 16 : V.O.D. $=6 / 10-2$; V.O.S. 6/10. Edge of disc clearly defined except that the demarcation between disc and fundus at upper and nasal side not clear, but as the disc on the opposite side presented the same appearance, the patient was discharged as cured. The disease existed one month before the operation and cleared up one month after the operation.

During the last two weeks of after-treatment Hyd. c. cret. 4 grs. with pot. iod. 20 grs. was daily administered (i.e., two weeks after operation), but before any drugs were administered the vision had improved from fingers at two metres to 6/15-4 and the colour scotoma had disappeared.

\title{
KRUKENBERG'S SPINDLE IN A CATARACT CASE
}

\section{BY}

\section{R. R. JAMES \\ LONDON}

I HAD never seen or heard of a case of Krukenberg's spindle before reading the proofs of Dr. Cardell's paper in the Brit. Jl. of Ophthal. in the April number, Vol: X, p. 198. The following case seems worthy to be recorded briefly :

A.F., a single woman, aged 63 years, attended my out-patients' department at St. George's Hospital, on April 17, 1926, with a mature cataract in her only useful eye. The history, traced from the hospital records, was as follows : She first attended in June, 1889, under the care of $\mathrm{Mr}$. Adams Frost; the notes of this first visit are rather fragmentary, but the vision with pupils dilated 
with homatropine and cocaine was noted as follows: R.E. $-6.0 \mathrm{sph} .=6 / 24$; L.E. $-14.0 \mathrm{sph} .=6 / 60$. In 1894 , a better result was recorded; R.E. $-10.0 \mathrm{sph} .=5 j 12$; L.E. $-14.0 \mathrm{sph} .=5 / 60$. In 1897 , the visual result was the same.

In 1898, she attended complaining of visual failure in the left eye, preceded by black spots of three weeks' duration. A shallow retinal detachment was discovered downwards and inwards, the area of detachment being limited by a patch of old choroidal atrophy. She was admitted and underwent the usual treatment of rest in bed with diaphoresis, and the subretinal fluid was tapped by Mr. Frost. She was discharged at the end of the year and on December 30 the condition was noted as unchanged. The next note of her attendance was in January, 1911, when I saw her myself and noted that the best visual result was 6/18 in the right eye with $-14.0 \mathrm{sph},-2.0 \mathrm{cyl}$. axis horizontal. The left eye was divergent and blind with an opaque lens.

She returned in April of last year with a mature cataract in the right eye, which, from the history, had been of rather rapid development for she had been able to pursue her avocation as a cook up to the beginning of this year.

The vision was less than $6 / 60$; projection of light was good. Many years ago I learnt from Mr. William Lang the importance of examining my cataract cases prior to operation, without and with a mydriatic; and so I instilled homatropine and cocaine, and when the pupil was well and evenly dilated I examined the cornea in order to exclude keratic precipitates. I was astonished to find an oval pigmented patch situated vertically in the cornea, and slightly towards the nasal side of the centre; this was composed of fine brown dots which with the loupe appeared to be situated deeply in the cornea. The appearance was almost exactly similar to the peppery deposit on the anterior capsule of the lens seen in some cases of persistent pupillary membrane; but the pupil was evenly dilated, no tags were present, and, moreover, the patch was in the cornea. It showed particularly well against the white background of the opaque lens. I diagnosed a Krukenberg's spindle and as I was due to leave town almost immediately for my holiday, advised the patient to come in for extraction on my return. This she did, and early in August I removed her cataract, performing an iridectomy before removing the lens. I did the iridectomy first instead of at the end of the extraction, which is my usual practice, because of the history of retinal detachment in the other eye; knowing that if vitreous escaped from a ruptured hyaloid and the lens sank back into the vitreous, the extraction of it with a vectis would be thereby facilitated.

The extraction was uneventful, except for the fact that the fixation forceps wounded a small subconjunctival vessel and the 
patient got the largest subconjunctival haematoma I have ever seen : at the end of the operation it stood up round the lower and inner part of the cornea, looking very much like a kidney with the hilum at the limbus. Before bandaging the eye I tapped this haematoma with a cut from a pair of scissors. Recovery was uneventful and the case left hospital at the end of the month.

'Tested in out-patients' department on September 1, 1926, the visual result was: R.E. +0.75 cyl. axis horizontal $=6 / 9$. There was a large myopic crescent, the macula was healthy as was the vitreous, and the spindle was very obvious; it could be seen with focal illumination by the naked eye. I could not discover any trace of a spindle in the blind eye.

Seen by the aid of the slit-lamp the change in the cornea appears to be more diffuse than one would be led to expect by simple examination with the loupe; to the latter the appearance was really that of a spindle more or less in the centre of the cornea.

The picture by Theodore Hamblin, Ltd., with the aid of the slit-lamp, shows the condition excellently. I am indebted to $\mathrm{Mr}$. Duke-Eider for the trouble he took in attending with the patient and showing the draughtsman exactly what was wanted.

\title{
TREATMENT OF TRACHOMA BY ACETIC ACID
}

BY

\author{
J. A. LeA \\ NATAL
}

Having seen lately in the British Journal of Ophthalmology several papers, more especially abstracts from foreign sources on the treatment of trachoma, and having noticed how varied the treatment was, and in some instances severe, I am encouraged to give my experience of a plan of treatment which I have found successful during the time that $I$ have practised as an ophthalmic surgeon in South Africa.

When first I came to South Africa several years ago I found trachoma very prevalent, more especially in the, dry, dusty upcountry districts; and had many severe and neglected cases to attend. I used the usual remedies with only moderate success. I then commenced this plan of treatment which I followed with success until I retired from practice a few years ago.

My method of procedure is as follows: I wash the eye and eyelids with a saturated solution of boracic acid. I then drop in a 0.5 per cent. solution of cocaine (I use Darier's solution which contains also adrenaline). I then take an instrument made for 